\title{
Promoção da saúde: um desafio para a atenção primária
}

\author{
Health promotion: a challenge for primary care \\ Promoción de la salud: un desafío para la atención primaria
}

Armando Henrique Norman. MSc em Antropologia Médica pela Durham University. editor.rbmfc@sbmfc.org.br

\begin{abstract}
Aliviar o sofrimento é um imperativo moral infindável, mas a obsessão contemporânea pela manutenção da saúde faz parte da persistente e recorrente ilusão do sonho humano de controlar o futuro. A atual manifestação desse sonho é mediada pela ciência, cujo novo Santo Graal é uma vida longa e sem sofrimento, que termina na velhice extrema, com rápido declínio e morte, também milagrosamente sem sofrimento. Iona Heath ${ }^{1}$
\end{abstract}

Nesta edição, a RBMFC traz artigos que abordam a promoção da saúde e prevenção de doenças, em seus vários matizes. O tema da promoção da saúde é bastante complexo e controverso sob o ponto de vista de sua operacionalização nos serviços da APS/ESF. De acordo com a OMS²:

[...] a promoçáo da saúde é o processo que empodera as pessoas, tanto no sentido de melhoria como de controle de sua saúde [...]. A saúde é, portanto, vista como recurso para o dia a dia, não como objetivo do viver. É um conceito positivo, que enfatiza recursos sociais e pessoais, bem como as capacidades físicas. Sendo assim, promoção da saúde não é apenas responsabilidade do setor da saúde, indo além de um estilo de vida saudável, rumo ao bem-estar.

A promoção da saúde tem na sua raiz conceitual o alívio do sofrimento das pessoas, e essa relação, apesar de não estar claramente explícita em sua definição, é muito importante para os profissionais da saúde. Na busca do alívio do sofrimento, existem açóes que pertencem ao campo dos serviços de saúde e açôes externas aos serviços de saúde. Estas últimas incluem moradia, educação, renda, alimentação, ecossistema estável, recursos sustentáveis, lazer, paz, trabalho com condições dignas, mobilidade, enfim, uma gama de açôes que visam o bem comum, a redistribuição das riquezas e a redução das desigualdades sociais ${ }^{2,3}$. Neste sentido, um exemplo concreto de promoção da saúde, internacionalmente reconhecido, é a política adotada pelo governo brasileiro com o programa Bolsa Família, que tem auxiliado na redução do sofrimento de milhóes de pessoas que viviam abaixo da linha da pobreza, ou seja, uma medida sanitária cujo núcleo de ação está fora dos serviços de saúde, mas que envolve a intersetorialidade ${ }^{4}$.

Já na esfera dos serviços de saúde, a promoção da saúde, ou seja, o alívio dos sofrimentos ocorre tradicionalmente de duas formas: açóes preventivas e açôes assistenciais envolvidas no ato de cuidar. Ao se ancorar a promoçấo da saúde no alívio do sofrimento, ter-se-ia um referencial a partir do qual seria possível construir estratégias mais efetivas para os serviços de saúde. Por exemplo, quando Starfield et al. ${ }^{5}$ questionam se é correto que quase metade das consulta médicas nos Estados Unidos se dediquem a check-ups, enquanto muitas pessoas carecem de acesso aos serviços quando têm algum problema de saúde, os autores estão indagando se é eticamente aceitável priorizar açôes preventivas, que, por definição, ocorrem sobre pessoas assintomáticas, em detrimento do atendimento de pessoas com sofrimento "real", ferindo os preceitos da equidade e da justiça social. Não seria este um desvio assistencial promotor da lei de cuidados inversos ${ }^{6}$, "[...] em que a disponibilidade de uma boa assistência médica tende a variar inversamente com a necessidade da população atendida"? 
No SUS, por vezes, não tem sido diferente, pois tradicionalmente se tem um discurso em que o "PSF deveria fazer promoção e prevenção da saúde" e que a demanda espontânea atrapalha essa "nobre missão" da APS/ESF. Isso resulta em agendas hipertrofiadas com atividades programáticas em detrimento de um acesso facilitado ao cuidado à saúde pelas equipes da $\mathrm{ESF}^{7}$.

Parece haver uma confusão relacionada à distinção entre a função principal e a função complementar das equipes da APS/ ESF, tanto no imaginário dos profissionais como dos gestores do SUS. A função principal das equipes da ESF é o alívio do sofrimento por meio do cuidado individual e familiar, ou seja, responder às necessidades da população contribuindo para a promoção da saúde ${ }^{8,9}$. Complementarmente, as equipes da ESF deveriam fazer atividades de promoção e prevenção, em âmbito micro social, cujos efeitos são difusos e leves, mas que contribuem para a melhoria da "consciência sanitária" e da organização popular para reivindicaçôes e para a participação na gestão local do SUS7.

Portanto, na operacionalização dos serviços da APS/ESF, a promoção da saúde não deveria estar conceitualmente dissociada das açôes assistenciais e/ou dos cuidados realizados pelos profissionais das equipes da ESF, pois a legitimidade destes e da própria APS/ESF consolida-se socialmente ao oferecer cuidado efetivo diante do sofrimento dos indivíduos. Como afirmado por Heath ${ }^{1}$, "[...] priorizar a prevenção em relação à cura é o tipo de slogan fácil de fazer, amado por políticos e gestores, mas que ignora sistematicamente as implicações desta retórica."

\section{Referências}

1. Heath I. In defence of a national sickness service. BMJ. 2007; (334): 19. PMid:17204798 PMCid:PMC1764107. http://dx.doi.org/10.1136/ bmj.39066.541678.B7

2. World Health Organization - WHO. Milestones in Health Promotion Statements from Global Conferences. WHO; 2009.

3. Gérvas J. Inteligencia sanitaria y atención primaria; V Seminario Internacional de Atención Primaria de Salud; 2010, Río de Janeiro. Río de Janeiro; 2010. Disponível em: http://189.28.128.100/dab/docs/eventos/5aps/apresentacoes/juan_gervas.pdf

4. Rasella D, Aquino R, Santos CA, Paes-Sousa R, Barreto ML. Effect of a conditional cash transfer programme on childhood mortality: a nationwide analysis of Brazilian municipalities. The Lancet. 2013; 382(9886): 57-64. Disponível em: http://www.ncbi.nlm.nih.gov/pubmed/23683599 http:// dx.doi.org/10.1016/S0140-6736(13)60715-1

5. Starfield B, Hyde J, Gérvas J, Heath I. The concept of prevention: a good idea gone astray? J Epidemiol Community Health. 2008; 62(7): 580-583. PMid:18559439. http://dx.doi.org/10.1136/jech.2007.071027

6. Hart JT. The Inverse Care Law. The Lancet. 1971; (Feb): 405-12. http://dx.doi.org/10.1016/S0140-6736(71)92410-X

7. Tesser CD, Norman AH. Repensando o acesso ao cuidado na Estratégia Saúde da Família. Saúde Soc. 2013. [No prelo].

8. Cassel EJ. The nature of suffering and the goals of medicine. N England J Med. 1982; 306(11): 639-45. PMid:7057823. http://dx.doi.org/10.1056/ NEJM198203183061104

9. Sweeney K. Science, society, suffering and the self: A commentary on general practice for the twenty first century. NZFP. 2005; 32(4): 221-4. 